14

\title{
О молекулярной природе различий в реакции сенсорных нейронов и фибробластов на уабаин
}

\author{
(C) М.М. Халисов, ${ }^{1}$ В.А. Пеннияйнен, ${ }^{1}$ С.А. Подзорова, ${ }^{1}$ А.В. Анкудинов, ${ }^{2,}$, , К.И. Тимощук, ${ }^{1}$ Б.В. Крылов ${ }^{1}$ \\ ${ }^{1}$ Институт ффизиологии им. И.П. Павлова РАН, \\ 199034 Санкт-Петербург, Россия \\ ${ }^{2}$ Физико-технический институт им. А.Ф. Иоффре РАН, \\ 194021 Санкт-Петербург, Россия \\ ฯ e-mail: alexander.ankudinov@mail.ioffe.ru
}

Поступило в Редакцию 18 сентября 2020 г.

В окончательной редакции 19 ноября 2020 г.

Принято к публикации 10 декабря 2020 г.

\begin{abstract}
Методом атомно-силовой микроскопии в физиологически адекватных условиях исследовали влияние уабаина на механические характеристики первичных сенсорных нейронов и фибробластов 10-12-дневных куриных эмбрионов. Фибробласты экспрессируют только $\alpha 1$-изоформу $\mathrm{Na}, \mathrm{K}-\mathrm{ATФазы,} \mathrm{а} \mathrm{сенсорные} \mathrm{нейроны}$ $\alpha 1-$ и $\alpha 3$-изоформы. Было обнаружено, что действие уабаина в концентрации, соответствующей эндогенному значению, приводит к увеличению жесткости мембраны сенсорных нейронов, что обусловлено, по-видимому, активацией не насосной, а трансдукторной функции Na,K-АТФазы. Действие уабаина в эндогенной концентрации не приводило к изменению механических характеристик фибробластов. Полученные результаты позволяют предположить, что эндогенный уабаин модулирует трансдукторную функцию именно $\alpha 3$-изоформы

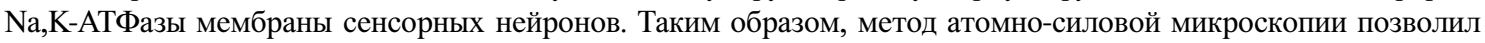
провести сравнительное исследование внутриклеточных сигнальных каскадов в живых клетках.
\end{abstract}

Ключевые слова: атомно-силовая микроскопия, сенсорные нейроны, фибробласты, уабаин, Na,К-АТФаза.

DOI: 10.21883/JTF.2021.05.50704.272-20

\section{Введение}

Натрий-калиевая (Na,К-АТФаза) - это фермент, присутствующий в плазматической мембране большинства эукариотических клеток. Хорошо изучена насосная функция

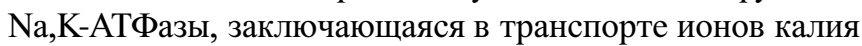
в клетку и натрия из нее за счет гидролиза АТФ. Эта функция имеет решающее значение для создания трансмембранного градиента концентрации ионов натрия и калия, а также осмотического баланса и регуляции объема клеток [1-6]. Многочисленные данные свидетельствуют о том, что помимо насосной, Na,K-АТФаза выполняет также трансдукторную функцию, выступая в качестве усилителя (трансдуктора) сигнала [7-9]. Взаимодействие кардиотонических стероидов (уабаина, дигоксина, маринобуфагенина) в субнаномолярных и наномолярных концентрациях, сходных с концентрациями, обнаруженными в плазме крови [10], с Na,K-АТФазой вызывает активацию различных сигнальных каскадов в кардиомиоцитах, эпителиальных клетках почек, нейронах и некоторых других типах клеток [8,9,11-14]. Эти каскады включают в себя активацию $\mathrm{Src}$, фосфолипазы C, МАРК, Akt и т. п. [13]. Na,K-АТФаза-опосредованная сигнализация участвует во многих физиологических процессах, включая рост клеток, дифференцировку, апоптоз, воспаление, сократимость мышц и функцию почек [15-19]. В первичном сенсорном нейроне был обнаружен новый механизм мембранной сигнализации, запускаемый уабаином в концентрации, соответствующей его эндогенным значениям (эндогенный уабаин $(Э У))$, функцию трансдуктора сигнала в котором выполняет Na,К-АТФаза [8,20,21]. ЭУ синтезируется в коре надпочечников и гипоталамусе [10,22]. В эндогенных концентрациях этот агент не может связываться с другими мишенями, кроме одной из изоформ $\mathrm{Na}, \mathrm{K}-\mathrm{ATФазы.}$ Остается неясным, какая из них вовлечена в этот процесс. Повышение уровня эндогенных кардиотонических стероидов приводит к возникновению патологических состояний, таких как артериальная гипертензия, почечная недостаточность, преэклампсия, фиброз и т. п. [5].

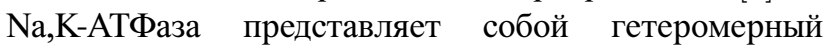
трансмембранный белок, состоящий из незаменимых $\alpha$ и $\beta$-субъединиц [23], а также необязательной третьей $\gamma$-субъединицы, экспрессия которых является тканеспецифичной $[3,5,19,24]$. Субъединицы $\alpha$ и $\beta \mathrm{Na}, \mathrm{K}-\mathrm{ATФазы}$ выполняют разные функции: $\alpha$-субъединица содержит сайты связывания для $\mathrm{Na}^{+}, \mathrm{K}^{+}$, кардиотонических стероидов (уабаина, дигаксина, маринобуфагенина) и АТФ, а $\beta$-субъединица необходима для образования $\alpha / \beta$-комплекса и его встраивания в плазматическую мембрану. $\alpha$-субъединица $\mathrm{Na}, \mathrm{K}-\mathrm{ATФазы} \mathrm{имеет} \mathrm{четыре}$ изоформы $(\alpha 1-\alpha 4)$, которые различаются паттернами экспрессии и функциональными свойствами. Уровни экспрессии изоформ зависят от различных факторов: стадии развития организма, типа клетки, вида ткани, действия определенных гормонов [3,19]. В некоторых клетках (фибробластах, адипоцитах, эритроцитах) присутствует 
только $\alpha 1$-изоформа [3,25]. В дополнение к $\alpha 1$-изоформе, которая присутствует почти во всех клетках организма, другие три экспрессируются тканеспецифичным образом. $\alpha 2$-изоформа в основном присутствует в скелетных мышцах, сердце и мозге, $\alpha 3$-изоформа преобладает в нервной ткани, а $\alpha 4$-изоформа была обнаружена в семенниках $[3,5,18,19,26]$. В нервной ткани $\alpha 1$-изоформа экспрессируется как в нейронах, так и в глиальных клетках, $\alpha 2$-изоформа в основном обнаруживается в астроцитах и олигодендроцитах, тогда как в нейронах в изобилии присутствует $\alpha 3$-изоформа $[3,6,19]$. В первичных нейронах спинальных ганглиев преимушественно экс-

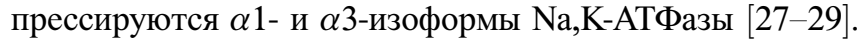

Тканеспецифичное распределение комплексов $\alpha / \beta$ и $\alpha / \beta / \gamma$ указывает на то, что каждая комбинация обладает уникальными клеточными функциями и, по-видимому, находится под контролем специфических для клетки регуляторных механизмов $[3,5,13,19]$.

Известно, что изоформы $\alpha$-субъединиц $\mathrm{Na}, \mathrm{K}$-АТФазы различаются чувствительностью к специфическому ингибитору уабаину [3,30]. Например, у грызунов $\alpha 1$-изоформа примерно на 2-3 порядка менее чувствительна к данной субстанции (константа диссоциации $\sim 50-450 \mu \mathrm{M})$, чем $\alpha 2-$ и $\alpha 3$-изоформы Na,K-АТФазы.

Различные внешние воздействия могут влиять на сложные физиологические внутриклеточные процессы, приводя к изменению физико-химических характеристик клеток. Одним из индикаторов состояния клетки служат ее механические свойства. Используя такие механические параметры, как жесткость, модуль Юнга, величина деформации, можно исследовать клеточную реакцию в ответ на внешние воздействия, в частности на уабаин [31,32]. Взаимодействие ЭУ с Na,K-АТФазой может приводить к активации различных сигнальных каскадов, что, в свою очередь, может оказывать влияние и на механические свойства клетки.

Одним из методов количественного изучения механических свойств клеток является атомно-силовая микроскопия (АСМ). В основе данного метода исследования поверхности лежит силовое взаимодействие между нанометрово-острым зондом и образцом. АСМ позволяет исследовать нативные клетки в физиологически адекватных условиях, обеспечивает прецизионный контроль силы и, как следствие, неразрушающее воздействие на клетку, дает возможность картировать механические характеристики клеток с высоким пространственным разрешением. Вследствие этих особенностей АCM зарекомендовала себя как эффективный инструмент для изучения механических свойств живых клеток [31-33].

Ранее с помощью АСМ было обнаружено, что первичные сенсорные нейроны демонстрируют тенденцию к увеличению жесткости мембраны под воздействием ЭУ $[34,35]$. В литературе отсутствуют данные о влиянии ЭУ на модуль Юнга других типов клеток. Первичные сенсорные нейроны экспрессируют $\alpha 1$ - и $\alpha 3$-изоформы

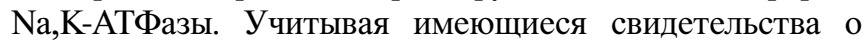
различной чувствительности к уабаину разных изоформ

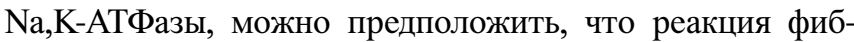
робластов, экспрессирующих только $\alpha 1$-изоформу, на воздействие ЭУ будет отлична от реакции нейронов. Настоящая работа посвящена сравнительному АCМ-исследованию механических характеристик двух типов клеток, различающихся по экспрессируемым изоформам

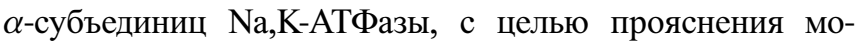
лекулярных механизмов ответа сенсорных нейронов и фибробластов на ЭУ.

\section{1. Методы исследования}

В настоящей работе использовался атомно-силовой микроскоп BioScope Catalyst (Bruker, США). Он оптимизирован для изучения биологических объектов - совмещен с инвертированным оптическим микроскопом Ахіо Observer Z1 (Carl Zeiss, Германия), оснащен нагревательным элементом под управлением термоконтроллера 335-й модели (Lake Shore Cryotronics, CША) для поддержания физиологически адекватной температуры объекта исследования. Кроме того, помимо стандартных статического (контактного) и динамического (прерывистоконтактного) режимов работы в данном атомно-силовом микроскопе реализован новый квазистатический режим PeakForce QNM, который хорошо подходит для исследования нативных клеток, поскольку зонд в этом режиме оказывает наиболее щадящее воздействие на их поверхность. Это достигается, с одной стороны, за счет того, что работа механизма обратной связи в данном режиме основана на непосредственном контроле нормальной силы воздействия на образец, а с другой стороны - на особенности алгоритма движения зонда, заключающейся в отскоке зонда от образца на заданное расстояние после их кратковременного контактного взаимодействия. Последнее позволяет снизить вред от разрушительной для нативных клеток латеральной компоненты силы. B PeakForce QNM зонд поточечно индентирует (продавливает) поверхность образца; производимый прямо во время сканирования анализ зависимостей силы от расстояния зонд-образец, силовых кривых, регистрируемых в каждой точке индентации, позволяет изучать механические характеристики клеток, картируя такие параметры как кажущийся модуль Юнга, амплитуда деформации. Подробную информацию о принципах изучения механических характеристик нативных клеток посредством АСМ можно, например, найти в работах [3639].

Методики выделения и подготовки нативных фибробластов сердца и сенсорных нейронов 10-12-дневных куриных эмбрионов к АСМ-исследованию подробно описаны в предыдущих работах $[40,41]$ соответственно. АСМ-сканирование клеток осуществлялось прямо в $40 \mathrm{~mm}$ пластиковых чашках Петри с питательной средой при постоянной температуре $\approx 37^{\circ} \mathrm{C}$. Клетки культивировали в питательной среде следующего состава: 45\% раствора Хенкса, 40\% среды Игла, 10\% фетальной сы- 
воротки коровы, $0.5 \mathrm{U} / \mathrm{ml}$ инсулина, $0.6 \%$ глюкозы, $2 \mathrm{mM}$ глютамина и $100 \mathrm{U} / \mathrm{ml}$ гентамицина. Для более надежной иммобилизации объектов исследования чашки Петри заранее обрабатывали веществами, усиливающими адгезию клеток к подложке: коллагеном для фибробластов и поли-L-лизином для сенсорных нейронов. Уабаин добавляли в культуральную среду к сенсорным нейронам за $72 \mathrm{~h}$ до исследования в концентрации $10^{-10} \mathrm{M}$ и фибробластам - в концентрациях $10^{-10}, 10^{-8}$ и $10^{-7} \mathrm{M}$. Контрольные клетки культивировались в стандартной питательной среде.

Перед исследованием клеток каждый зондовый датчик подвергался калибровке: сначала измерялась чувствительность кантилевера к отклонению на сапфировом образце из стандартного тестового набора для режима PeakForce QNM PFQNM-SMPKIT-12M (Bruker, CШA), затем по методу тепловых шумов определялась константа жесткости кантилевера. После помещения зонда в питательную среду - чашку Петри с клетками, производилось повторное измерение чувствительности к отклонению на чистом, свободном от клеток, участке подложки. Это позволяло проконтролировать правильность переюстировки системы регистрации отклонений кантилевера и убедиться, что после погружения в питательную среду к зонду не прикрепились фрагменты клеток.

Ниже приведены модели АСМ-зондов и параметры сканирования в режиме PeakForce QNM, с которыми осуществлялось изучение влияния уабаина на механические характеристики клеток.

Сенсорные нейроны + уабаин $10^{-10} \mathrm{M}$ : модель зонда - SNL-(D) (Bruker, CША), пиковая сила $-1 \mathrm{nN}$, частота и амплитуда вертикального движения зонда соответственно $-250 \mathrm{~Hz}$ и $1000 \mathrm{~nm}$, частота строчной развертки $-0.1 \mathrm{~Hz}$, АСМ-кадр - 512 или $1024 \times 128$.

Фибробласты + уабаин $10^{-10}$ M: SNL-(D), пиковая сила $-3 \mathrm{nN}$, частота и амплитуда вертикального движения зонда соответственно - $250 \mathrm{~Hz}$ и $500 \mathrm{~nm}$, частота строчной развертки $-0.1 \mathrm{~Hz}$, АСМ-кадр $1024 \times 128$ точек.

Фибробласты + уабаин $10^{-8} \mathrm{M}$ : SNL-(D), пиковая сила $-3 \mathrm{nN}$, частота и амплитуда вертикального движения зонда соответственно - $250 \mathrm{~Hz}$ и $1000 \mathrm{~nm}$, частота строчной развертки - $0.1 \mathrm{~Hz}$, АСМ-кадр $512 \times 128$ точек.

Фибробласты + уабаин $\quad 10^{-7} \mathrm{M}$ : модель зонда CSG10 (НТ-МДТ СИ, Россия), пиковая сила $-3 \mathrm{nN}$, частота и амплитуда вертикального движения зонда соответственно $-250 \mathrm{~Hz}$ и $1000 \mathrm{~nm}$, частота строчной развертки $-0.15 \mathrm{~Hz}$, АСМ-кадр - $128 \times 128$ точек.

Механические свойства клеток характеризовали с помощью величины кажущегося модуля Юнга. Значение данного параметра определялось автоматически в каждой точке индентации по модели Снеддона, согласно которой форма зонда аппроксимируется конусом [42]. Полученные АСМ-карты распределения кажущегося модуля Юнга по поверхности клеток обрабатывали с помощью программ для анализа АCM-изображений Bruker NanoScope Analysis версий 1.40 и 1.80 , а также Gwyddion 2.55 [43]. В случае фибробластов определяли среднее значение модуля Юнга по всей поверхности клетки, попавшей в АСМ-кадр, за исключением краевых областей, где толщина исследуемого объекта минимальна и может составлять всего несколько сотен нанометров. Затем, используя средние значения модуля Юнга каждого фибробласта, производили расчет средних величин данного параметра в контрольной группе клеток и группе после воздействия уабаина в разных концентрациях. В различных сериях экспериментов модели зондов и параметры сканирования не были одинаковы. В связи с этим сравнение средних значений модуля Юнга для группы фибробластов после воздействия уабаина в данной концентрации производилось с соответствующими значениями группы контрольных клеток, АСМ-сканирование которых осуществлялось зондами той же модели и с идентичными параметрами сканирования. В случае первичных сенсорных нейронов средние значения модуля Юнга определялись по всей площади сомы клетки (граничные области сомы с крутыми склонами клетки исключались из анализа). Далее аналогично фибробластам вычислялись, а затем сравнивались между собой средние значения параметра для группы сенсорных нейронов, культивированных в присутствии ЭУ, и контрольной группы клеток.

Непараметрический статистический $U$-критерий Манна-Уитни применялся для оценки значимости различий между величинами модуля Юнга в экспериментальной и контрольной группах клеток (при $p<0.05$ различия считались значимыми).

\section{2. Результаты и обсуждение}

Сенсорные нейроны и фибробласты для изучения с помощью атомно-силового микроскопа отбирали, используя инвертированный оптический микроскоп. АСМ-сканированию подвергали лишь надежно иммобилизованные на подложке интактные клетки без видимых загрязнений плазматической мембраны. Посредством светового микроскопа визуально состояние клеток контролировали на протяжении всего АСМ-эксперимента.

Фибробласты распластываются по подложке и, как следствие, имеют пологие склоны. При этом за исключением краевой области их толщина позволяет соблюдать условие максимального соотношения величины деформации к толщине клетки, при котором вкладом твердой подложки в результаты измерения механических характеристик можно пренебречь [36]. Кроме того, фибробласты, как правило, обладают развитым цитоскелетом, и легко выдерживают механическое воздействие со стороны АСМ-зонда, не повреждаясь. Все это делает фибробласты удобным объектом для изучения с помощью АСМ. В отличие от фибробластов сенсорные нейроны представляют собой не столь простой объект 
Таблица 1. Результаты измерения модуля Юнга контрольных сенсорных нейронов и клеток после воздействия ЭУ

\begin{tabular}{c|c|c|c|c|c}
\hline \multicolumn{3}{c|}{ Контрольные нейроны } & \multicolumn{2}{c}{ Нейроны при воздействии ЭУ $10^{-10} \mathrm{M}$} \\
\hline № клетки & $E_{c p}, \mathrm{kPa}$ & № клетки & $E_{c p}, \mathrm{kPa}$ & № клетки & $E_{c p}, \mathrm{kPa}$ \\
\hline 1 & 34 & 9 & 35 & 1 & 77 \\
2 & 70 & 10 & 81 & 2 & 72 \\
3 & 72 & 11 & 219 & 4 & 286 \\
4 & 70 & 12 & 27 & 5 & 284 \\
6 & 55 & 13 & 155 & 6 & 296 \\
7 & 112 & 15 & 108 & 8 & 314 \\
\hline
\end{tabular}

Пр имечан и е. $E_{c p}-$ средний кажущийся модуль Юнга сомы каждого сенсорного нейрона.

для исследования, поскольку имеют выпуклую веретенообразную форму и крутые склоны, поэтому во время АСМ-сканирования их легче повредить или открепить от подложки. Следует отметить, что эти геометрические особенности сенсорных нейронов приводят также к ошибочным измерениям механических характеристик на границах клеток, так как механизм обратной связи не всегда успевает достаточно быстро среагировать на резкое изменение высоты сканируемого объекта по отношению к уровню гладкой подложки. Кроме того, наличие толстых пучков актиновых микрофиламентов, стресс-фибрилл, часто в большом количестве встречающихся в фибробластах, не характерно для нейронов [44], что делает нейроны более чувствительными к механическому повреждению. С учетом вышесказанного в настоящей работе при АСМ-сканировании сенсорных нейронов частота строчной развертки и пиковая сила взаимодействия зонд-клетка были минимизированы.

Механическое воздействие нанометрово-острого АСМ-зонда в течение приблизительно 15-20 min (время, затрачиваемое на получение одного кадра АСМизображения) в большинстве случаев не приводило к повреждению плазматической мембраны сенсорных нейронов и фибробластов и не вызывало видимых изменений их механических свойств. В редких случаях, когда клетка все же повреждалась, это происходило c сенсорными нейронами, данные исключались из дальнейшего анализа.

В табл. 1 приведены данные, демонстрирующие результаты АСМ-индентирования сенсорных нейронов после воздействия ЭУ в концентрации $10^{-10} \mathrm{M}$ и контрольных клеток. Сравнение значений модуля Юнга показывает, что величина параметра в среднем почти в три раза выше у экспериментальных нейронов, чем у контрольных. Таким образом, зарегистрировано достоверное увеличение жесткости поверхности сенсорных нейронов после действия ЭУ (U-критерий, $p<0.05)$. Известно, что в сенсорных нейронах экспрессируются $\alpha 1$ - и $\alpha 3$-изоформы Na,K-АТФазы [27,29,45-47].

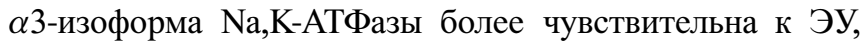

чем $\alpha 1[3,30,48]$. Таким образом, обнаруженное нами увеличение жесткости мембраны сенсорного нейрона при действии ЭУ позволяет предположить, что данный эффект связан с активацией трансдукторной функции $\alpha 3$-изоформы Na,K-АТФазы.

Несмотря на то что ЭУ $\left(10^{-10} \mathrm{M}\right)$ приводил к достоверному росту жесткости мембраны сенсорных нейронов, при исследовании воздействия ЭУ в той же концентрации не было обнаружено его влияния на механические свойства фибробластов. Интересно, что в более высоких концентрациях уабаин $\left(10^{-8}\right.$ и $\left.10^{-7} \mathrm{M}\right)$ также не влиял на механические свойства фибробластов.

Данные, полученные в результате АСМ-индентирования фибробластов, сведены в табл. 2. Видно, что значения модуля Юнга у клеток, культивированных в присутствии уабаина, и у контрольных клеток различаются слабо.

Пример АСМ-данных с контрольными фибробластами из экспериментов по исследованию действия на клетки уабаина в разных концентрациях приведен на рисунке.

В сериях экспериментов с разной концентрацией уабаина наблюдалась значительная разница в величинах модуля Юнга у фибробластов. Такое расхождение могло быть вызвано следующими причинами. Известно, что механические свойства клеток зависят от скорости воздействия $[49,50]$. Так, в экспериментах с наименьшей концентрацией исследуемого вещества $\left(10^{-10} \mathrm{M}\right) \mathrm{ACM}-$ индентирование проводилось с более высокой скоростью относительно остальных случаев из-за меньшей выбранной амплитуды вертикального движения зонда $500 \mathrm{~nm}$ - против 1000 nm в других экспериментах. Различие между значениями модуля Юнга в экспериментах с двумя другими концентрациями уабаина можно связать с тем, что в них для АСМ-индентирования фибробластов применялись разные модели зондов с неодинаковыми величинами отношения высоты зонда к длине консоли кантилевера. Ранее в работе [41] подобный результат зависимости кажущегося модуля Юнга сенсорных нейронов от отношения высоты зонда к длине консоли кантилевера был объяснен тем, что рост этого отношения 
Таблица 2. Результаты измерения модуля Юнга контрольных фибробластов и клеток после воздействия уабаина в разных концентрациях

\begin{tabular}{c|c|c|c}
\hline $\begin{array}{c}\text { Концентрация } \\
\text { уабаина }\end{array}$ & $10^{-10} \mathrm{M}$ & $10^{-8} \mathrm{M}$ & $10^{-7} \mathrm{M}$ \\
\hline Контроль & $480 \pm 100 \mathrm{kPa}(n=6)$ & $230 \pm 220 \mathrm{kPa}(n=13)$ & $70 \pm 50 \mathrm{kPa}(n=29)$ \\
Уабаин & $460 \pm 230 \mathrm{kPa}(n=6)$ & $290 \pm 240 \mathrm{kPa}(n=13)$ & $\begin{array}{c}70 \pm 70 \mathrm{kPa}(n=36) \\
0.48\end{array}$
\end{tabular}

Пр имечание. $n$ - число изученных клеток.
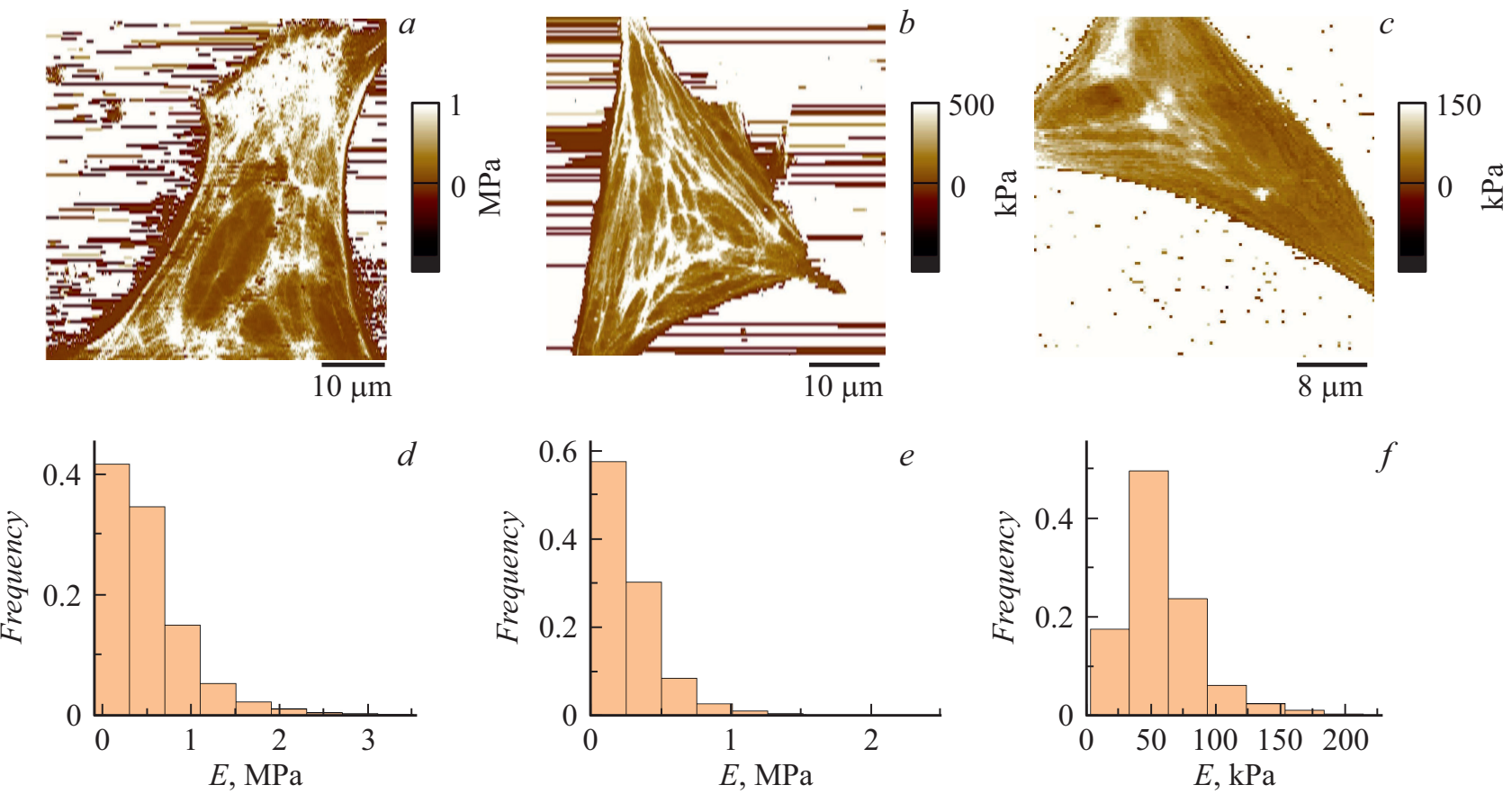

АСМ-карты модуля Юнга контрольных фибробластов из экспериментов с концентрацией уабаина: $a-10^{-10}, b-10^{-8}$, $c-10^{-7} \mathrm{M} ; d-f-$ распределения модуля Юнга $(E)$ по поверхности фибробластов $(a-c)$ соответственно.

способствует защемлению кончика зонда на поверхности образца, что приводит к аномальному прогибу кантилевера с вытекающим из этого ошибочным определением механических характеристик клетки.

Несмотря на различия в абсолютных значениях кажущегося модуля Юнга в экспериментах с разной концентрацией уабаина, в рамках эксперимента с одной и той же концентрацией всегда использовались одинаковые модели зондов и неизменные параметры АСМсканирования. Это обеспечивало надежность полученных результатов при сравнении механических характеристик фибробластов.

Таким образом, полученные результаты свидетельствуют, что ни одна исследованная концентрация уабаина не влияла на механические свойства фибробластов. В отличие от этого нами ранее было показано, что вещество, действующее непосредственно на цитоскелет клеток, колхицин, вызывает рост жесткости фибробластов куриных эмбрионов и фибробластов крысы $[51,52]$. Отсутствие влияния ЭУ на механические свойства ис- следуемых клеток может быть связано с тем, что фибробласты в отличие от сенсорных нейронов экспрессируют только уабаин-резистентную $\alpha 1$-изоформу

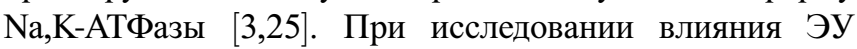
на механические характеристики сенсорных нейронов, экспрессирующих не только $\alpha 1$-, но и $\alpha 3$-изоформу

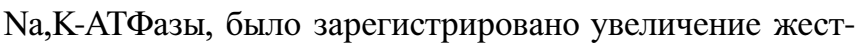
кости мембраны исследованных клеток. Полученные экспериментальные данные позволяют предположить, что выявленное действие ЭУ на сенсорные нейроны может быть результатом активации трансдукторной функции

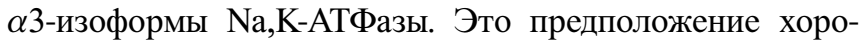
шо согласуется с имеющимися в литературе данными, согласно которым уабаин в значительно более высоких концентрациях может активировать трансдуктурную функцию $\alpha 1$-изоформы Na,K-АТФазы в разных клетках [53-55]. Uddin и соавторы показали, что в цитотрофобластах клеточной линии SGHPL-4 маринобуфагенин и уабаин в концентрациях 10 и $100 \mathrm{nM}$ индуцируют активацию Jnk, p38 и Src, активируют каспазы 9 и 3/7, 
и повышают секрецию IL-6, т.е. эти кардиотонические стероиды запускают апоптотический каскад [53]. Необходимо отметить, что после культивирования фибробластов с уабаином апоптоз мы не наблюдали. Обработка фибробластов легких человека (W138) уабаином в концентрации $10^{-6} \mathrm{M}$ и выше значительно увеличивала уровень экспрессии мРНК ИЛ-6. Более низкие концентрации вещества $\left(10^{-9}\right.$ и $\left.10^{-8} \mathrm{M}\right)$ не вызывали такой реакции клеток [55]. По данным других исследований культивирование фибробластов сердца взрослой мыши с уабаином в концентрации $10^{-5} \mathrm{M}$ индуцировало активацию Erk1/2 и значительно увеличивало количество активной Src-киназы. Также уабаин стимулировал синтез коллагена и пролиферацию фибробластов сердца. По мнению авторов, пролиферативный эффект может быть результатом комбинированного действия уабаина, как на насосную, так и на трансдукторную функции $\alpha 1$-изоформы Na,K-АТФазы [54]. Учитывая все вышесказанное и полученные нами экспериментальные данные, можно заключить, что уабаин в столь низкой эндогенной концентрации $\left(10^{-10} \mathrm{M}\right)$ не влияет на механические характеристики фибробластов, поскольку эти клетки экспрессируют только уабаин-резистентную $\alpha 1$-изоформу $\mathrm{Na}, \mathrm{K}-\mathrm{ATФазы.} \mathrm{В} \mathrm{то} \mathrm{время} \mathrm{как} \mathrm{сенсорные} \mathrm{нейроны,}$

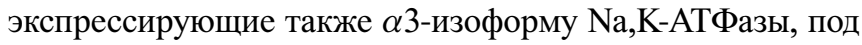
действием ЭУ изменяют свои механические свойства, по-видимому, за счет активации трансдукторной функции $\alpha 3$-изоформы Na,K-АТФазы.

\section{Заключение}

В последние годы в литературе широко обсуждается вопрос о роли трансдукторной функции Na,K-АТФазы в клетке $[13,14,20,56]$. Вероятно, действие уабаина является не только ткане-, но и клеточно-специфичным. Это предположение подтверждают экспериментальные данные, полученные в настоящей работе. Исследуемые в работе клетки различаются паттернами экспрессии изоформ $\alpha$-субъединицы Na,K-АТФазы. Сенсорные нейроны, экспрессирующие $\alpha 1$ - и $\alpha 3$-изоформы $\mathrm{Na}, \mathrm{K}-\mathrm{ATФазы} \mathrm{[27-}$ 29], под действием ЭУ демонстрируют увеличение жесткости мембраны, а фибробласты, экспрессирующие лишь одну уабаин-резистентную $\alpha 1$-изоформу [3,25,30], не меняют механических характеристик под действием данного вещества. Полученные результаты позволяют предположить, что ЭУ активирует трансдукторную функцию $\alpha 3$-изоформы Na,K-АТФазы и приводит к изменению механических характеристик сенсорных нейронов в результате активации внутриклеточных каскадных процессов. Можно заключить, что метод АСМ позволяет изучать механизмы внутриклеточной сигнализации в живых клетках.

\section{Финансирование работы}

Работа сотрудников Института физиологии им. И.П. Павлова РАН выполнена при поддержке
Российского фонда фундаментальных исследований (проект № 18-015-00079), а также программы фундаментальных научных исследований государственных академий наук на 2013-2020 г. (ГП-14, раздел 64).

\section{Соблюдение этических стандартов}

Эксперименты были разработаны в соответствии с Директивой Совета Европейских сообществ от 24 ноября 1986 г. (86/609/ЕЭС). Местный комитет по уходу и использованию животных Института физиологии им. И.П. Павлова РАН утвердил все экспериментальные методики с животными, разрешение № 12/03 (20.04.2018).

\section{Конфликт интересов}

Авторы заявляют, что у них нет конфликта интересов.

\section{Список литературы}

[1] J.C. Skou. J. Am. Soc. Nephrol., 23 (11), 394 (1957).

[2] J.C. Skou, M. Esmann. J. Bioenerg. Biomembr., 24 (3), 249 (1992). DOI: $10.1007 / \mathrm{BF} 00768846$

[3] G. Blanco, R.W. Mercer. Am. J. Physiol., 275 (5), F633 (1998). DOI: 10.1152/ajprenal.1998.275.5.F633

[4] J.H. Kaplan. Annu. Rev. Biochem., 71, 511 (2002). DOI: 10.1146/annurev.biochem.71.102201.141218

[5] E. Silva, P. Soares-da-Silva. Int. Rev. Cell Mol. Biol., 294, 99 (2012). DOI: 10.1016/B978-0-12-394305-7.00002-1

[6] M.V. Clausen, F. Hilbers, H. Poulsen. Front Physiol., 8, 371 (2017). DOI: 10.3389/fphys.2017.00371

[7] P. Kometiani, J. Li, L. Gnudi, B.B. Kahn, A. Askari, Z. Xie. J. Biol. Chem., 273 (24), 15249 (1998). DOI: $10.1074 / \mathrm{jbc} .273 .24 .15249$

[8] Б.В. Крылов, А.В. Дербенев, С.А. Подзорова, М.И. Людыно, А.В. Кузьмин, Н.Л. Изварина. Физиол. журн., 85 (2), 225 (1999). [B.V. Krylov, A.V. Derbenev, S.A. Podzorova, M. Liudyno, A.V. Kuz'min, N.L. Izvarina. Ross. Fiziol. Zh. Im. I. M. Sechenova, 85 (2), 225 (1999).]

[9] M. Haas, A. Askari, Z. Xie, J. Biol. Chem., 275 (36), 27832 (2000). DOI: 10.1074/jbc.M002951200

[10] J.M. Hamlyn, M.P. Blaustein, S. Bova, D.W. DuCharme, D.W. Harris, F. Mandel, W.R. Mathews, J.H. Ludens. Proc. Natl. Acad. Sci. USA, 88 (14), 6259 (1991). DOI: $10.1073 /$ pnas.88.14.6259

[11] S.J. Khundmiri, M.A. Metzler, M. Ameen, V. Amin, M.J. Rane, N.A. Delamere. Am. J. Physiol. Cell Physiol., 291 (6), C1247 (2006). DOI: 10.1152/ajpcell.00593.2005

[12] V. Buckalew. Am. J. Physiol. Heart Circ. Physiol., 297 (6), H1972 (2009). DOI: 10.1152/ajpheart.01002.2009

[13] X. Cui, Z. Xie. Molecules, 22, 990 (2017). DOI: $10.3390 /$ molecules 22060990

[14] M.P. Blaustein. Am. J. Physiol. Cell Physiol., 314 (1), C3 (2018). DOI: 10.1152/ajpcell.00196.2017

[15] J. Li. Na, K-ATPase as a Signaling Transducer (Stockholm, 2007)

[16] E.V. Lopatina, I.L. Yachnev, V.A. Penniyaynen, V.B. Plakhova, S.A. Podzorova, T.N. Shelykh, I.V. Rogachevsky, I.P. Butkevich, V.A. Mikhailenko, A.V. Kipenko, B.V. Krylov. Medicinal Chem., 8 (1), 33 (2012). DOI: $10.2174 / 157340612799278531$ 
[17] F. Lai, N. Madan, Q. Ye, Q. Duan, Z. Li, S. Wang, S. Si, Z. Xie. J. Biol. Chem., 288 (19), 13295 (2013). DOI: $10.1074 /$ jbc.M113.467381

[18] D. Lichtstein, A. Ilani, H. Rosen, N. Horesh, S.V. Singh, N. Buzaglo, A. Hodes. Int. J. Mol. Sci., 19 (8), 2314 (2018). DOI: $10.3390 /$ ijms 19082314

[19] F.K. Khalaf, P. Dube, A. Mohamed, J. Tian, D. Malhotra, S.T. Haller, D.J. Kennedy. Int. J. Mol. Sci., 19 (9), 2576 (2018). DOI: $10.3390 /$ ijms 19092576

[20] B.V. Krylov, I.V. Rogachevskii, T.N. Shelykh, V.B. Plakhova. New Non-Opioid Analgesics: Understanding Molecular Mechanisms on the Basis of Patch-Clamp and QuantumChemical Studies (Bentham Sci. Publ., Sharjah, 2017). DOI: $10.2174 / 97816080593001170101$

[21] V.A. Penniyaynen, V.B. Plakhova, I.V. Rogachevsky, S.G. Terekhin, S.A. Podzorova, B.V. Krylov. Pathophysiology, 26 (3-4), 245 (2019). DOI: 10.1016/j.pathophys.2019.06.003

[22] Kawamura, J. Guo, Y. Itagaki, C. Bell, Y. Wang, G.T. Jr. Haupert, S. Magil, R.T. Gallagher, N. Berova, K. Nakanishi. Proc. Natl. Acad. Sci. USA, 96 (12), 6654 (1999). DOI: 10.1073/pnas.96.12.6654

[23] J.B. Lingrel, T. Kuntzweiler, J. Biol. Chem., 269 (31), 19659 (1994).

[24] K. Geering. J. Bioenerg Biomembr, 37 (6), 387 (2005). DOI: $10.1007 / \mathrm{s} 10863-005-9476-\mathrm{x}$

[25] J.L. Brodsky. J. Biol. Chem., 265 (18), 10458 (1990).

[26] R. Holm, M.S. Toustrup-Jensen, A.P. Einholm, V.R. Schack, J.P. Andersen, B. Vilsen. Biochim. Biophys. Acta, 1857 (11), 1807 (2016). DOI: 10.1016/j.bbabio.2016.08.009

[27] M. Mata, G.J. Siegel, V. Hieber, M.W. Beaty, D.J. Fink. Brain Res., 546 (1), 47 (1991).

DOI: $10.1016 / 0006-8993(91) 91157-\mathrm{v}$

[28] D. Romanovsky, A.E. Moseley, R.E. Mrak, M.D. Taylor, M. Dobretsov. J. Comp. Neurol., 500 (6), 1106 (2007). DOI: $10.1002 /$ cne. 21218

[29] D. Paul, R.D. Soignier, L. Minor, H. Tau, E. Songu-Mize, H.J. Gould 3rd. J. Neurol. Sci., 340 (1-2), 139 (2014). DOI: $10.1016 /$ j.jns.2014.03.012

[30] A. Mobasheri, J. Avila, I. Cozar-Castellano, M.D. Brownleader, M. Trevan, M.J.O. Francis, J.F. Lamb, P. Martin-Vasallo. Biosci. Reports., 20 (2), 51 (2000). DOI: $10.1023 / \mathrm{a}: 1005580332144$

[31] M. Li, D. Dang, L. Liu, N. Xi, Y. Wang. IEEE IEEE Trans Nanobioscience, 16 (6), 523 (2017). DOI: $10.1109 /$ TNB.2017.2714462

[32] X. Deng, F. Xiong, X. Li, B. Xiang, Z. Li, X. Wu, C. Guo, X. Li, Y. Li, G. Li, W. Xiong, Z. Zeng J. Nanobiotechnology, 16 (1), 102 (2018). DOI: 10.1186/s12951-018-0428-0

[33] E. Spedden, C. Staii. Int. J. Mol. Sci., 14 (8), 16124-40 (2013). DOI: $10.3390 / \mathrm{ijms} 140816124$

[34] M.M. Khalisov, A.V. Ankudinov, V.A. Penniyaynen, D. Dobrota, B.V. Krylov Acta Physiol. Hung., 102 (2), 125 (2015). DOI: $10.1556 / 036.102 .2015 .2 .2$

[35] M.M. Khalisov, A.V. Ankudinov, V.A. Penniyaynen, T.E. Timoshenko, K.I. Timoshchuk, M.V. Samsonov, V.P. Shirinsky. IOP Conf. Series: Mater. Sci. Eng., 256 (012010), 1 (2017).

DOI:10.1088/1757-899X/256/1/012010

[36] T.G. Kuznetsova, M.N. Starodubtseva, N.I. Yegorenkov, S.A. Chizhik, R.I. Zhdanov. Micron, 38(8), 824 (2007). DOI:10.1016/j.micron.2007.06.011

[37] N. Gavara. A. Microsc. Res. Tech., 80 (1), 75 (2017). DOI: $10.1002 /$ jemt.22776
[38] М.М. Халисов. Автореф. канд. дисс. (СПб НИУ ИТМО, СПб, 2018)

[39] К.И. Тимощук. Автореф. канд. дисс. (СПб НИУ ИТМО, СПб, 2019)

[40] М.М. Халисов, В.А. Пеннияйнен, Н.А. Есикова, А.В. Анкудинов, Б.В. Крылов. Письма в ЖТФ, $43(1)$, 89 (2017). DOI: 10.21883/PJTF.2017.01.44094.16394 [M.M. Khalisov, V.A. Penniyaynen, B.V. Krylov, A.V. Ankudinov, N.A. Esikova. Tech. Phys. Lett., 43 (1), 85 (2017).]

[41] А.В. Анкудинов, М.М. Халисов, В.А. Пеннияйнен, С.А. Подзорова, К.И. Тимощук, Б.В. Крылов. Письма в ЖТФ, $44(15), \quad 38 \quad$ (2018). DOI: 10.21883/PJTF.2018.15.46438.17351 [A.V. Ankudinov, M.M. Khalisov, V.A. Penniyaynen, S.A. Podzorova, K.I. Timoshchuk, B.V. Krylov. Tech. Phys. Lett., 44 (15), 38 (2018).]

[42] I. Sneddon. INT. J. Eng. Sci., 3, 47 (1965). DOI: 10.1016/0020-7225(65)90019-4

[43] D. Nečas, P. Klapetek. Cent. Eur. J. Phys., 10 (1), 181 (2012).

[44] G. Pigino, Y. Song, L.L. Kirkpatrick, S.T. Brady. In: Basic Neurochemistry: Principles of Molecular, Cellular and Medical Neurobiology, edition: 8th, ed. by S.T. Brady, G.J. Siegel, R.W. Albers, D.L. Price (Academic Press, English, 2012), p. 109.

[45] M. Dobretsov, S.L. Hastings, J.R. Stimers. Neuroscience, 93, 723 (1999). DOI: 10.1016/s0306-4522(99)00122-0

[46] A. Parekh, A.J. Campbell, L. Djouhri, X. Fang, S. McMullan, C. Berry, C. Acosta, S.N. Lawson. J. Physiol., 588 (Pt 21), 4131 (2010). DOI: 10.1113/jphysiol.2010.196386

[47] I.J. Edwards, G. Bruce, C. Lawrenson, L. Howe, S.J. Clapcote, S.A. Deuchars, J. Deuchars. J. Neurosci., 33 (24), 9913 (2013). DOI: 10.1523/JNEUROSCI.5584-12.2013

[48] W.J. O’Brien, J.B. Lingrel, E.T. Wallick. Arch. Biochem. Biophys., 310 (1), 32 (1994). DOI: 10.1006/abbi.1994.1136

[49] B. Fabry, G.N. Maksym, J.P. Butler, M. Glogauer, D. Navajas, N.A. Taback, E.J. Millet, J.J. Fredberg. Phys. Rev. E, 68, 041914-1-18 (2003). DOI: 10.1103/PhysRevE.68.041914

[50] E. Moeendarbary, A. R. Harris. Wiley Interdiscip Rev. Syst. Biol. Med., 6 (5), 371 (2014). DOI: 10.1002/wsbm.1275

[51] К.И. Тимощук, М.М. Халисов, В.А. Пеннияйнен, Б.В. Крылов, А.В. Анкудинов. Письма в ЖТФ, 45 (18), 44 (2019). DOI: 10.21883/PJTF.2019.18.48238.17878 [K.I. Timoshchuk, M.M. Khalisov, V.A. Penniyaynen B.V. Krylov, A.V. Ankudinov. Tech. Phys. Lett., 45 (9), 947 (2019).] DOI:10.1134/S1063785019090293

[52] М.М. Халисов, В.А. Пеннияйнен, С.А. Подзорова, К.И. Тимощук, А.В. Анкудинов, Б.В. Крылов. ЖТФ, 90 (11), 1938 (2020). DOI: 10.21883/JTF.2020.11.49987.118-20

[53] M.N. Uddin, D. Horvat, S.S. Glaser, B.M. Mitchell, J.B. Puschett. J. Biol. Chem., 283, 17946 (2008). DOI: $10.1074 /$ jbc.m800958200

[54] L.E.M. Quintas, S.V. Pierre, L. Liu, Y. Bai, X. Liu, Z.J. Xie. J. Mol Cell Cardiol., 49 (3), 525 (2010). DOI: $10.1016 /$ j.yjmcc.2010.04.015

[55] M. Akashi, A.H. Loussararian, D.C. Adelman, M. Saito, H.P. Koeffler. J. Clin. Invest., 85, 121 (1990). DOI: $10.1172 /$ jci114401

[56] A. Askari. Pharmacol. Res. Perspect., 7 (4), e00505 (2019). DOI: $10.1002 /$ prp2.505 